\title{
HABILIDADES CULINÁRIAS NA PANDEMIA DE COVID-19: DIÁLOGOS POSSÍVEIS ENTRE GASTRONOMIA E SOBERANIA E SEGURANÇA ALIMENTAR E NUTRICIONAL
}

\author{
Juliana Dias Rovari Cordeiro ${ }^{1}$ \\ Filipe Pessoa dos Santos ${ }^{2}$ \\ Paula Ramos ${ }^{3}$
}

\begin{abstract}
Resumo: Neste artigo, buscamos aprofundar a discussão sobre os efeitos da pandemia da Covid-19 no ato de cozinhar e se alimentar em casa. Partimos de uma ideia ampliada de Gastronomia para discutir seu potencial educativo no desenvolvimento de habilidades culinárias e a promoção da alimentação saudável, com base no Guia Alimentar para a População Brasileira. Para tal, apresentamos aproximações entre o campo de conhecimento da Gastronomia com o da Soberania e Segurança Alimentar e Nutricional (SSAN), por meio da reflexão dos conceitos e políticas públicas de alimentação e nutrição, e também pela observação do Índice de Isolamento Social com buscas realizadas na internet pelos termos "receitas culinárias", "pão" x "bolo", entre os meses de fevereiro e agosto de 2020. Espera-se dessa forma compreender como a gastronomia pode contribuir para fortalecer as estratégias Educação Alimentar e Nutricional (EAN) com uma perspectiva dialógica e problematizadora.
\end{abstract}

Palavras-chave: Gastronomia; Habilidades Culinária; Soberania e Segurança Alimentar e Nutricional.

\section{CULINARY SKILLS IN THE COVID-19 PANDEMIC: POSSIBLE DIALOGUES BETWEEN GASTRONOMY AND SOVEREIGNTY AND FOOD AND NUTRITIONAL SECURITY}

\begin{abstract}
In this article, we seek to deepen the discussion about the effects of the Covid-19 pandemic on cooking and eating at home. We started from an expanded idea of Gastronomy to discuss its educational potential in the development of culinary skills and the promotion of healthy eating, based on the Food Guide for the Brazilian Population. To this end, we present approximations between the field of knowledge of Gastronomy with that of Sovereignty and Food and Nutritional Security (SSAN), through the reflection of the concepts and public policies of food and nutrition, and also by observing the Social Isolation Index with searches carried out on the internet by the terms "culinary recipes", "bread" and "cake", between the months of February and August 2020. It is hoped that this way we understand how gastronomy can contribute to strengthen the strategies Food and Nutrition Education (EAN) with a dialogical and problematizing perspective.
\end{abstract}

Keywords: : Gastronomy; Culinary Skills; Sovereignty and Food and Nutritional Security.

\footnotetext{
${ }^{1}$ Bacharela em Comunicação Social (FACHA), mestra em Educação em Ciências e Saúde (Nutes/UFRJ) e doutora em História das Ciências e das Técnicas e Epistemologia (HCTE/UFRJ). Realiza estágio pós-doutoral no Programa de Pós-Graduação em Educação em Ciências e Saúde (PPGECS/Nutes), onde é professora colaboradora e pesquisadora do Grupo de Estudos Sobre Desigualdades na Educação e na Saúde (Gedes). Orcid: 0000-0003-32854409. E-mail: julianadiasrc@gmail.com.

${ }^{2}$ Bacharel em Gastronomia pela Universidade Federal do Rio de Janeiro. Mestrando no Programa de Pós-Graduação de Educação em Ciências e Saúde, do Instituto NUTES de Educação em Ciências e Saúde da Universidade Federal do Rio de Janeiro. ORCID: 0000-0002-9130-0118. E-mail: filipe.p2s@gmail.com.

${ }^{3}$ Possui doutorado em Educação em Ciências e Saúde pela Universidade Federal do Rio de Janeiro (2010); mestrado em Tecnologia Educacional para Saúde pela Universidade Federal do Rio de Janeiro (2006) e bacharelado em Ciências Biológicas pela Universidade Federal do Rio de Janeiro (1999). Atualmente, é professora adjunta no Instituto NUTES de Educação em Ciências e Saúde (NUTES)/UFRJ. ORCID: 0000-0002-8231-1237. E-mail: paularamos.ufrj@gmail.com.
} 


\title{
HABILIDADES CULINARIAS EN LA PANDEMIA COVID-19: POSIBLES DIÁLOGOS ENTRE GASTRONOMÍA Y SOBERANÍA Y SEGURIDAD ALIMENTARIA Y NUTRICIONAL
}

\begin{abstract}
Resumem: Reflexionar sobre los diálogos y convergencias, así como sobre las divergencias, entretejidos en los sistemas alimentarios requiere, minimamente, una comprensión ampliada de toda la tela de araña que lo envuelve y nos invita a romper con las miradas compartimentadas de la tríade sociedad-naturaleza-cultura. La ciencia de la nutrición ha estado históricamente influenciada por el cartesianismo biológico y para pensar la formación y actuación desde perspectivas amplias es necesario conocer la diversidad de los sistemas alimentarios y discutir alternativas al modelo hegemónico. La alternativa que se presenta aquí a través de la agroecología, en su tríade ciencia-movimientopráctica. La discusión busca romper con la lógica compartimentada, ya que los/las nutricionistas son fundamentales en la búsqueda y construcción de sistemas alimentarios sostenibles y saludables.

Palabras clave: Seguridad Alimentaria y Nutricional; Agricultura Sostenible; Ciência de la nutrición
\end{abstract}

\section{Introdução}

A crise sanitária provocada pela pandemia da Covid-19 afetou de forma significativa o cozinhar e a comensalidade. Essas práticas culturais orientam a articulação das dimensões organizativa da produção material e simbólica da vida social, e afetiva, estabelecida pelos vínculos, laços e pela coesão comunitária. Nesta perspectiva, o Guia Alimentar para a População Brasileira atribui à comensalidade o valor de elemento fundamental para o contexto alimentar, descrevendoa como uma orientação básica que busca a valorização do compartilhamento das atividades em torno do comer, principalmente nos lares das famílias, cenário que foi diretamente influenciado pelas condições impostas pela pandemia do coronavírus.

O Observatório de Políticas de Segurança Alimentar e Nutricional da Universidade de Brasília (UNB) produziu no ano de 2020, a partir do seu projeto de extensão chamado "MultiplicaSSAN" uma pesquisa que buscou estudar as mudanças que a pandemia da Covid-19 causou na comensalidade dos brasileiros.

De acordo com o estudo, as pessoas passaram a se alimentar mais nos seus lares em comparação com o momento pré-pandêmico, e as companhias mais frequentes foram as próprias famílias, além de ter aumentado o tempo que as pessoas se dedicavam ao cozinhar, cenário descrito como um reflexo da maior disponibilidade de tempo devido ao isolamento social (RIZZOLO et al, 2020).

Neste contexto, buscamos aprofundar a discussão sobre os efeitos da pandemia no ato de cozinhar e se alimentar em casa. As recomendações (micro) biológicas de prevenção para o controle do vírus, enfatizadas nas orientações sanitárias de cuidados e técnicas de manipulação e preparo de alimentos, e o compartilhamento, a reunião e a partilha da comida foram identificadas 
como "fatores de risco" para o contágio, promovendo adaptações às práticas alimentares (RIZZOLO et al, 2020).

Com o isolamento social, o fechamento de escolas, de restaurantes, e o aumento significativo do trabalho remoto, muitos domicílios passaram a se envolver mais frequentemente com a preparação de refeições. Como causas desse movimento, diversos artigos de jornais e revistas de ampla circulação citam o receio de contágio por comidas preparadas por terceiros (NOGUEIRA, 2020), o prazer de cozinhar e a necessidade de manter a saúde mental (FOLHA VITÓRIA, 2020), a preocupação com alimentação saudável (KOWALTOWSKI, 2020), a possibilidade de cultivar os laços de afeto e cuidado (TUCHLINSKI, 2020) e, ainda, a possibilidade de garantir a renda (CARDOSO, 2020).

Essa aproximação com o alimento e o ato de cozinhar se reflete nas mídias digitais, intensificando a busca e o acesso a perfis que compartilham receitas e experiências com a cozinha. São inúmeras as fotos compartilhadas dos feitos culinários por iniciantes e veteranos, sobressaindo-se a preparação de pães e bolos, dando origem, inclusive, ao movimento apelidado de "pãodemia". A expressão foi criada pela portuguesa e apresentadora de programa culinário Filipa Gomes. No início da pandemia, ela compartilhou no seu Instagram $^{4}$ uma receita de pão com quatro ingredientes, que dispensa fogão à lenha e força física. A ideia era que seus seguidores pudessem preparar facilmente seus pães em casa. A postagem viralizou com mais de 600 mil visualizações e a ideia de fazer pão ganhou adesão não apenas para saciar a fome, mas por ser uma atividade prazerosa.

Para Certeau (2011), o pão "é a memória de um maior bem-estar duramente conquistado no decorrer das gerações anteriores". Segundo o autor, este alimento representa um monumento para conjurar o sofrimento e a fome, o que faz sentido pensar o interesse em assar pão no contexto de incertezas, medos e inseguranças gerados pela pandemia. O pão suscita o respeito mais arcaico, é quase sagrado. Nas palavras do autor, pão é um memorial (CERTEAU, 2011). Assim, pode-se afirmar que uma das características desse contexto pandêmico é a busca por comidas reconfortantes, que tragam prazer e exerçam funções terapêuticas para o alívio de tensões e estresse.

A prática de fazer bolos, que também aumentou sua popularidade na internet durante a pandemia, é descrita por Antônio Prata ${ }^{5}$ como "uma demonstração de carinho" que se come só para ficar feliz e é um "elogio à alegria de estarmos vivos. A cronista Nina Horta chamou de

\footnotetext{
${ }^{4}$ https://www.instagram.com/p/B9terQ4pN2E/

${ }^{5}$ http://blogdoantonioprata.blogspot.com/2007/10/time-ishoney.html?fbclid=IwAR3sQgrLZirKJeGJ0YRWwbV4rVtTvvblVpmqsBbL3uM0EnqCiiddy3SNmNE
} 
Comida de Alma "aquela que consola, escorre garganta abaixo quase sem precisar ser mastigada, na hora de dor, de depressão, de tristeza pequena (...) Dá segurança, enche o estômago, conforta a alma, lembra a infância e os costumes (...). (HORTA, 2020/n.p).

Neste artigo, partimos de uma ideia ampliada de Gastronomia para discutir seu potencial na ampliação e desenvolvimento das habilidades culinárias durante o isolamento social. Para tal, primeiramente, apresentamos a noção ampliada de Gastronomia e os diálogos possíveis com a Soberania e Segurança Alimentar e Nutricional (SSAN), o papel das mídias digitais como mediadoras das habilidades culinárias e, posteriormente, analisamos os dados de buscas no Google relacionadas à culinária - por meio da Plataforma Google Trends - durante o período de isolamento social entre fevereiro e agosto de 2020.

Dessa forma, buscamos encontrar padrões e correlações que possam ajudar na compreensão do interesse em desenvolver habilidades culinárias durante a pandemia, especialmente com comidas que confortam como o pão e o bolo. Nosso objetivo é, com base nas relações apresentadas, provocar o debate acerca das contribuições do campo da Gastronomia para fortalecer as estratégias Educação Alimentar e Nutricional (EAN) com uma perspectiva dialógica e problematizadora.

\section{Da sofisticação às habilidades culinárias: por um conceito ampliado de gastronomia}

As práticas culinárias resultam da vontade e necessidade de adaptação dos Estados a diferentes grupos sociais, em especial a elite, a contextos históricos específicos que impactam a estrutura e organização social. A França é o exemplo emblemático entre cozinha e nação. O poder identificador da cozinha é um atributo fundamental do que é ser francês. Desde o século XVIII, com a criação de instituições e escritos, a gastronomia deixou de ser um produto culinário aristocrático e elitista para se converter em uma pedra angular da identidade republicana francesa, após a revolução (MATTA, 2014).

A ascensão da gastronomia muito se associa a valorização do alimento nas relações sociais, como por exemplo os banquetes; a construção e valorização de comportamentos refinados à mesa; a escalada do status de chefs de cozinha, já que durante muito tempo a atividade de cozinhar, em diferentes povos, era reservada a pessoas escravizadas; e também a compreensão da capacidade de diferenciação social que a comida pode proporcionar (FREIXA, CHAVES, 2013).

Poulain (2013) retrata a influência cultural francesa sobre a Europa como fruto da construção e atuação daquilo que ele denominou de "dinâmica da moda". De acordo com o autor, a burguesia francesa ascende economicamente, buscando imitar as maneiras aristocráticas. Assim, 
a Gastronomia se estabeleceu como referência, partindo do intenso incentivo que os reis absolutistas deram aos chefs, até a ascensão dos grandes restaurantes como reflexo do fim dos serviços que esses cozinheiros ofereciam à nobreza, que então não mais existia pós Revolução e ascensão da burguesia (FRANCO, 2001; FREIXA, CHAVES, 2013).

No século XIX, a noção de gastronomia, que significa legislar sobre o estômago, é interpretada pela primeira vez de forma interdisciplinar em uma obra de divulgação científica chamada "A Fisiologia do Gosto", publicada em 1826 pelo advogado francês Jean-Anthelme Brillat-Savarin. O autor afirma que se trata de um "conhecimento fundamentado de tudo o que se refere ao homem, na medida em que se alimenta", governando a vida do ser humano e exercendo influência em todas as classes sociais (BRILLAT-SAVARIN, 1996). Relaciona a gastronomia com diferentes áreas de saberes, tais como história natural, física, química, culinária, comércio e economia política. Segundo ele, o fim da gastronomia é cuidar da conversação da humanidade mediante a melhor alimentação possível e que esta rege todo o ciclo da vida, do nascimento à morte.

Santich $(1996 ; 2004)$ percorre as premissas de Savarin e amplia essa noção para as formas de produção de alimentos e, ainda, como, onde, e o porquê, estão postos para o consumo. Santich compreende que valores diversos influenciam a gastronomia, sejam eles crenças, aspectos culturais, sociais, históricos ou filosóficos. Para a autora (SANTICH, 2004), pensar a gastronomia se refere a

[...] produção de alimentos e aos meios pelos quais os alimentos são produzidos; a economia política da comida; o tratamento de alimentos, seu armazenamento, transporte e processamento; sua preparação e cozimento; refeições e maneiras; a química da comida, digestão e os efeitos fisiológicos da comida; escolhas alimentares e costumes e tradições (SANTICH, 2004, p 18).

Em acordo com Savarin (1995) e Santich (2004), observamos que a gastronomia é transdisciplinar e envolve as dimensões da existência humana (social, política, cultural e espiritual). Gillespie e Cousins (2001) também enaltecem essa multiplicidade ao descrever que a gastronomia pode estabelecer relações com diferentes assuntos, profissões, ofícios e campos científicos. Ambos os autores mencionados percebem ser visível que a ação de relativizar a gastronomia proporciona uma janela para o mundo, uma maneira de compreender as culturas. $\mathrm{O}$ que nos faz pensar ser intensamente limitante estabilizar a gastronomia somente no discurso do ápice gustativo, normatizado por práticas postas como quase eruditas.

Petrini (2009) propôs os princípios da ecogastronomia, ou seja, aportou um pensamento ecologizado. O autor também revisita a definição de Savarin, reconhece ser um campo de 
conhecimento científico, porém, atualiza a noção de gastronomia ao inter-relacioná-la à 14 áreas, a saber: botânica, genética e outras ciências naturais; física e química; agricultura, zootecnia e agronomia; ecologia; antropologia; sociologia; geopolítica; economia política; comércio; tecnologia; cozinha; fisiologia; medicina e epistemologia. O sociólogo, que é fundador do movimento Slow Food, também afirma ser gastronomia cultura material e imaterial, liberdade de escolha, ciência que estuda a felicidade, educação e prazer.

A gastronomia, afirma Petrini, "nos permite viver da melhor forma possível, de acordo com os recursos disponíveis e nos estimula a melhorar nossa própria existência” (PETRINI, 2009). Esta última afirmação é similar à de Savarin, mas contextualizada com uma noção ecológica. Para ele, a gastronomia começa com a semente. “A cozinha é uma forma de proteção da produção de pequena escala, economia, biodiversidade e ecossistema" (PETRINI, 2016).

No Brasil, Helisa de Castro, Rodrigo Maciel e Maria Eunice Maciel (2016), pesquisadores do campo da antropologia, propõem uma compreensão semelhante às demais apresentadas ao atribuir à gastronomia, o status de campo de conhecimento capaz de gerar possibilidades de se estudar as sociedades na qual vivemos. Nessa perspectiva, gastronomia é:

[...] uma prática cultural relacionada à alimentação, sendo possível perceber suas diferentes manifestações em contextos globais mas não menos localizados. Seja a prática gastronômica realizada por um chef conceituado em sua "cozinhalaboratório" ou por comunidades tradicionais nas cerâmicas que estalam no fogo de chão o que sobressaltam são as questões anteriormente evocadas como o prazer, a comensalidade e as relações estabelecidas pelos atos de comer e de cozinhar. Isso porque seria incoerente estabelecer critérios valorativo-distintivos às práticas culturais, que em toda a sua complexidade, ainda que manifestadas de formas díspares, apresentam significados e simbolismos particulares que não devem (ou deveriam ser hierarquizados) (CASTRO, MACIEL, MACIEL, 2016, p 26).

Em 2015, o tema da Gastronomia encampou um debate entre representantes do segmento, da Segurança Alimentar e Nutricional (SAN), da nutrição, da agroecologia e do poder público para formular o Marco Referencial da Gastronomia como Cultura no Estado do Rio de Janeiro (Lei $\mathrm{N}^{\mathrm{o}}$ 7180/2015) (RIO DE JANEIRO, 2015). De acordo com o Marco, apresenta-se a seguinte definição:

I - cultura reconhecida como patrimônio de grupos familiares, imigrantes, migrantes, povos e comunidades tradicionais, como os indígenas, os quilombolas, as comunidades de matriz africana ou de terreiro, os extrativistas, os caiçaras e os pescadores artesanais.

II - estando relacionada aos conhecimentos tradicional, popular e científico, que representam os modos de vida, produção, utilização/preparação dos alimentos e da alimentação, sob a perspectiva social, cultural e política. 
III - uma das diversas formas de sociabilidade e de transmissão da cultura - dos saberes, dos sabores, dos cheiros, da história, da memória e do afeto; aproximando o local de produção com o local de consumo, de quem produz alimentos de quem prepara e consome, fortalecendo a identidade cultural de uma população.

IV - arte expressada na criação de receitas, combinação de ingredientes e apresentação dos alimentos, como também fonte de inspiração para as demais artes, tais como a literatura, a pintura, a música, a poesia, o cinema, a fotografia e a dança.

V - compromisso com a saúde, a nutrição, o uso dos recursos naturais e as práticas agrícolas, com respeito aos profissionais envolvidos no trabalho do campo à mesa, tornando-se concreta e acessível com a prática culinária e o compartilhamento da refeição (RIO DE JANEIRO, 2015).

É a partir dessas contribuições que construiremos este debate, compreendendo a gastronomia sob o que Soares et al (2020) apresentam como uma perspectiva inclusiva. , e assim percebê-la para além das concepções de distinção, de valor, de sofisticação e de normatização, nos ajuda a compreender sua transição pelas diferentes esferas da existência humana, pela estrutura e organização social e pelos vínculos que se estabelecem entre cultura, biodiversidade e território, presente no cotidiano e que transcende uma função profissional. Desta forma, promove-se uma relativização que proporciona enxergar a gastronomia como "fenômeno envolvente que traz em si diferenciações e particularidade, mas que se manifesta na ampla sociedade contemporânea" (CASTRO, MACIEL, MACIEL, 2016)

Há ainda que se considerar que os conceitos devem ser flexíveis e atualizáveis. Portanto, a construção do conceito ampliado de gastronomia, especialmente no Brasil, deve priorizar uma perspectiva do Sul Global, reconhecendo os saberes ancestrais, pensamentos e cosmologias dos povos indígenas e africanos.

\section{Diálogos possíveis: gastronomia e Soberania e Segurança Alimentar e Nutricional (SSAN)}

Com base nesse conjunto de reflexões que apontam para um conceito ampliado de gastronomia, propomos um diálogo com a Soberania e Segurança Alimentar e Nutricional (SSAN). Compreendida como um campo sociopolítico que se organiza a partir da década de 80, é fruto do reconhecimento da interdependência entre Soberania Alimentar e Segurança Alimentar e Nutricional. A Soberania Alimentar diz respeito ao:

[...] direito dos povos definirem suas próprias políticas e estratégias sustentáveis de produção, distribuição e consumo de alimentos que garantam o direito à alimentação para toda a população, com base na pequena e média produção, respeitando suas próprias culturas e a diversidade dos modos camponeses, pesqueiros e indígenas de produção agropecuária, de comercialização e gestão dos espaços rurais, nos quais a mulher desempenha um papel fundamental [...]. A soberania alimentar é a via para se erradicar a fome e a desnutrição e garantir 
a segurança alimentar duradoura e sustentável para todos os povos. (Fórum Mundial sobre Soberania Alimentar, Havana, 2001).

E a Segurança Alimentar e Nutricional (SAN):

Consiste na realização do direito de todos ao acesso regular e permanente a alimentos de qualidade, em quantidade suficiente, sem comprometer o acesso a outras necessidades essenciais, tendo como base práticas alimentares promotoras de saúde, que respeitem a diversidade cultural e que sejam ambiental, cultural, econômica e socialmente sustentáveis". (BRASIL, 2006).

Para além da quantidade e da qualidade dos alimentos, a política de SAN, instituída em 2006, preconiza as bases da Alimentação Adequada e Saudável, compreendida como:

A realização de um direito humano básico, com a garantia ao acesso permanente e regular, de forma socialmente justa, a uma prática alimentar adequada aos aspectos biológicos e sociais dos indivíduos, de acordo com o ciclo de vida e as necessidades alimentares especiais, pautada no referencial tradicional local. Deve atender aos princípios da variedade, equilíbrio, moderação, prazer (sabor), às dimensões de gênero e etnia, e às formas de produção ambientalmente sustentáveis, livre de contaminantes físicos, químicos, biológicos e de organismos geneticamente modificados (CONSEA, 2007, p 9).

Nesse contexto, destaca-se a publicação do Guia Alimentar para a População Brasileira (BRASIL/MS, 2014), que trouxe como primeiro princípio que "a alimentação é mais do a ingestão de nutrientes". Com isso, a visão biomédica da alimentação, centrada prioritariamente em nutrientes, é confrontada com uma abordagem complexa, em que se considera a maneira como os alimentos são preparados, as dimensões sociais, culturais e ecológicas que envolvem o ato de se alimentar, da semente à mesa. De acordo com esse princípio a saúde e o bem-estar podem ser impactados pelas práticas alimentares

O Guia apresenta entre as suas recomendações do Guia trazem dez passos da alimentação saudável. O sétimo passo é “desenvolver, exercitar e partilhar habilidades culinárias”. Orienta-se a quem tem essas habilidades, que estimule crianças e jovens, sem distinção de gênero. Caso não as tenha, o guia sugere adquiri-las por meio de conversas com pessoas que sabem cozinhar, pedir receitas aos familiares, amigos e colegas, ler livros, consultora a internet e até fazer cursos.

O desenvolvimento de habilidades pessoais é um dos cinco campos centrais de ação ${ }^{6}$ da Promoção da Saúde (BUSS, 2009), definida como “o processo de capacitação da comunidade para atuar na melhoria da sua qualidade de vida e saúde, incluindo uma maior participação no controle desse processo" (BRASIL, 2002, p.19). A partir do campo da Promoção da Saúde e da concepção

\footnotetext{
${ }^{6}$ Os demais campos são: elaboração e implementação de políticas públicas saudáveis, Criação de ambientes favoráveis a saúde, reforço da ação comunitária e Reorientação do sistema de saúde.
} 
ampliada de saúde, entendida como "resultante das condições de alimentação, habitação, educação, renda, meio ambiente, trabalho, transporte, emprego, lazer, liberdade, acesso e posse da terra e acesso a serviços de saúde" (CNS, 1986), podemos considerar que o ato de cozinhar colabora para desenvolver habilidades que promovem saúde. Também se apresenta como uma estratégia de aprendizagem para estimular a população a conhecer mais sobre sua comida, reconhecer a biodiversidade e as práticas alimentares locais, articulando esses conhecimentos com as implicações econômicas e políticas do sistema alimentar. Desta forma, vislumbra-se caminhos, a partir da cozinha, que fortaleçam uma maior participação e controle da produção e abastecimento alimentar de seus territórios.

De acordo com o Guia Alimentar, as habilidades culinárias fazem parte da compreensão e superação dos obstáculos para se promover a comida de verdade, pois "O enfraquecimento da transmissão de habilidades culinárias entre gerações favorece o consumo de alimentos ultraprocessados" (BRASIL, 2014). Os demais desafios apresentados são a informação, oferta de alimentos, custo, tempo e publicidade. Para fins deste artigo, abordaremos apenas as habilidades culinárias.

Cozinhar é apontada pelo documento como uma atividade que pode auxiliar a compreensão e superação dos obstáculos de promover a alimentação saudável. No entanto, essa tarefa não deve ficar a cargo de um só membro da família, como as mulheres. Todos devem ocupar o espaço da cozinha, participando das as etapas da produção e consumo de alimentos, incluindo a louça, armazenamento e descarte.

A prática culinária está inserida também como uma das estratégias para promover a Educação Alimentar e Nutricional (EAN), entendida como um "campo de conhecimento e de prática contínua e permanente, transdisciplinar, intersetorial e multiprofissional, que visa promover a prática autônoma e voluntária de hábitos alimentares saudáveis” (BRASIL, 2012).

No Marco Referencial da EAN para as políticas públicas, um dos princípios para as ações de EAN é a "comida e o alimento como referências; valorização da culinária como prática emancipatória" (BRASIL, 2013). O ato de cozinhar é associado à autonomia, cuidado e autocuidado. Saber preparar o próprio alimento também permite praticar as informações técnicas e amplia o conjunto de possibilidades dos indivíduos, conforme o documento.

O Marco sublinha que a prática culinária também facilita a reflexão e o exercício das dimensões sensoriais, cognitivas e simbólicas da alimentação. No referido documento, a comunicação é entendida como um conjunto de processos mediadores da EAN, que, para ser efetivada, deve ser pautada em alguns critérios, entre os quais, “construção partilhada dos saberes, 
práticas e soluções; valorização do conhecimento, da cultura e do patrimônio alimentar; e relações horizontais" (BRASIL, 2013). São propostas alinhadas com a visão freireana de comunicação e educação popular crítica e problematizadora e, também, nos ajuda a refletir sobre as mídias digitais como mediadoras para o desenvolvimento das habilidades culinárias.

Em 2015 (BRASIL, 2015), o Consea realizou a V Conferência Nacional de SAN com o tema "Comida de verdade no campo e na cidade: por direitos e soberania alimentar", em Brasília e publicou o manifesto da Comida de Verdade, compreendida como:

É a salvaguarda da vida. É saudável tanto para o ser humano quanto para o planeta. Garante os direitos humanos, o direito à terra e ao território, à alimentação de qualidade e em quantidade adequada em todo o curso da vida. Respeita o direito das mulheres, a diversidade dos povos indígenas, comunidades quilombolas, povos tradicionais de matriz africana/ povos de terreiro, povos ciganos, povos das florestas e das águas, demais povos e comunidades tradicionais e camponeses, desde a produção ao consumo. Protege e promove as culturas alimentares, a sociobiodiversidade, as práticas ancestrais, o manejo das ervas e da medicina tradicional e a dimensão sagrada dos alimentos (...). A comida de verdade não mata nem por veneno nem por conflito (BRASIL, 2015, p 1).

Esta compreensão conecta todas as dimensões da existência humana, em diálogo com uma visão de mundo que converge ser humano, natureza e o sagrado numa concepção complexa da alimentação saudável, que por sua vez está alinhada a proposta de um conceito ampliado de gastronomia.

Observamos que no campo da SAN, o ato de cozinhar é destacado como uma estratégia de promoção da alimentação saudável. A complexidade da alimentação apresentada nos documentos se alinha com a concepção ampliada de gastronomia, reunida neste artigo. A comida de verdade, segundo o manifesto, começa com o aleitamento materno e segue por todo o ciclo de vida. A ideia é similar ao que escreve Savarin sobre a gastronomia, a qual engloba “do nascimento à morte”. De igual forma, as preocupações culturais e ecológicas estão em diálogo com os princípios da ecogastronomia de Petrini. Cabe destacar que, no Plano Nacional de SAN (2016-2019), o Desafio 5 "promover e proteger a alimentação adequada e saudável da população brasileira, com estratégias de EAN e medidas regulatórias" trouxe como meta fortalecer a ecogastronomia.

A partir de 2017, criou-se a Rede Brasileira de Pesquisa em SSAN (Rede PENSSAN). A iniciativa é voltada para promover as pesquisas acadêmicas do campo da Alimentação e Nutrição, Agricultura, Ciências Sociais e Humanas, que adotam uma perspectiva intersetorial, portanto interdisciplinar. Dedica especial atenção às políticas públicas, dialogam com as organizações e os movimentos sociais e reconhecem diferentes modos de produção de conhecimento. O objetivo é gerar conhecimento para incidir na realidade e nas políticas públicas, tendo como horizonte a 
equidade, a justiça e a realização do Direito Humano à Alimentação Adequada (DHAA), na perspectiva de uma ciência cidadã (MALUF, 2017, p. 1-2).

Diante do exposto, identificamos que as habilidades culinárias oferecem possibilidades de diálogos e articulação entre a Gastronomia e a Soberania e Segurança Alimentar e Nutricional. As políticas de SAN enfatizam o desenvolvimento dessas habilidades, que se constituem em uma prática central para o campo de conhecimento da gastronomia. De igual forma a SSAN deve dialogar com a gastronomia.

\section{Vamos cozinhar em casa? As mídias digitais como mediadoras das habilidades culinárias na pandemia}

O desenvolvimento social dos seres humanos e nossa construção histórica confunde-se com a história do aparecimento contínuo de novas mídias comunicacionais, da oralidade às trocas de mensagens pelas redes digitais. A multiplicação nos modos de acessibilidade da digitalização provoca tanto as mídias tradicionais e as digitais. Com isso, cresce a diversidade semiótica das mídias, aumentam as misturas entre elas e multiplicam-se as possibilidades de seus usos (SANTELLA, 2010).

Em um cenário pandêmico, a relação por meio das tecnologias digitais tornou-se a principal forma de relacionamento e proximidade entre as pessoas. Santaella (2010) situa as práticas e processos comunicacionais como espaços ubíquos por serem espaços hiperconectados, de hiperlugares, múltiplos espaços, mentes multiconectadas, compondo inteligências fluídas. Os espaços ubíquos permitem que múltiplas realidades desfilem de modo simultâneo em nossa mente (p. 18). De acordo com a autora, é o ser humano que é o produtor e consumidor das mídias digitais; é o corpo vivo que recebe a profusão de imagens, sons e informação; é no corpo vivo que elas são combinadas, transformadas e integradas; é o corpo vivo que projeta novas imagens, sons e informação no mundo (SANTELLA, 2010).

A mídia social Instagram, criada em 2010, possui mais de 3 bilhões de usuários em todo mundo. Ao menos uma vez por dia, $89 \%$ dos jovens verificam suas contas, e as mulheres fazem o check-up com mais frequência. Seis entre 10 adultos tem uma conta no Instagram, e 35\% da audiência global é entre 25 e 34 anos. O Brasil é o país da América Latina que mais tem usuários ativos do Instagram e o segundo em todo o mundo (ASLAM, 2020). A alimentação é um dos temas de destaque desta rede no país. As hashtags "gastronomia" possui 12.6 milhões de publicações, e a "comida de verdade", soma 7.7 milhões. 
Giard (1996) situa as práticas culinárias no nível mais elementar, necessário e desprezado da vida cotidiana. É no dia a dia que ela localiza as "artes do fazer": táticas populares que geram maneiras singulares na hora de transpor as regras e utilizar os produtos impostos pelas políticas sociais na vida real. Na cozinha, "cada refeição exige a capacidade inventiva de uma miniestratégia para fazer mudança, por exemplo, quando falta um ingrediente ou não se dispõe do utensílio próprio para determinada receita" (Ibidem, 1996).

A autora (Ibidem, 1996) denomina de saber prático os procedimentos físicos que complementam o saber intelectual na hora de cozinhar. Esta tarefa necessita de um intermediário habilidoso capaz de compartilhar tal conhecimento. Mas, como essa informação cultural geralmente é transmitida de forma sutil na rotina diária, a presença de um mediador, ou uma mediadora, pode ser imperceptível (PELERANO, 2014). As mídias sociais podem ser consideradas como mediadoras dos aprendizados culinários. Desde o surgimento da internet no Brasil, sites de culinária, que antecederam as mídias, já tinha popularidade e, no contexto de pandemia, a necessidade de preparar alimentos levou a uma busca por ensinamentos para cozinhar no dia a dia.

O encontro, ou reencontro com o cômodo da cozinha, revelou as possibilidades de aprendizados, estratégias para enfrentar o cotidiano de preparar refeições diariamente e até geração de renda. Em meio à diversidade, nota-se a busca por desenvolver as habilidades culinárias, em que observamos como o conceito ampliado de gastronomia pode contribuir para desenvolver em diálogo com a perspectiva da comida de verdade, da EAN e da SAN.

\section{Caminhos para tecer aproximações entre Gastronomia e SSAN}

Assumimos como premissa, o fato de que o período de isolamento social decorrente da pandemia da Covid-19 acarretou mudanças nas práticas alimentares de parte da sociedade brasileira (RIZZOLO et al, 2020) impondo a necessidade de maior dedicação ao ato de cozinhar em casa. Este aspecto levou à cozinha muitas pessoas acostumadas a se alimentar na rua ou a terceirizarem a produção de alimentos em suas residências. Em relação a isso, com o objetivo de identificar esse movimento ao longo do período de isolamento, combinamos dados relativos a termos de busca no Google com os dados do índice de isolamento social ao longo do tempo, buscando encontrar padrões e correlação entre essas duas variáveis.

Para acompanhar a evolução do isolamento social, utilizamos o Índice de Isolamento Social, que é calculado diariamente, por meio de dados de localização fornecidos e 
habilitados em celulares pessoais, disponibilizados pela empresa Inloco ${ }^{7}$. Os dados, são distribuídos temporal e espacialmente, sendo possível acompanhar o índice médio tanto do Brasil, quanto dos estados. Para o estudo, utilizamos os dados brasileiros, desde o dia 24 de fevereiro quando foi detectado o primeiro caso do coronavírus no Brasil.

Em relação às mudanças relacionadas aos conhecimentos e práticas culinárias ao longo desse período, nos baseamos em dados fornecidos pela plataforma Google Trends, que é uma ferramenta gratuita do Google que oferece um panorama das tendências, em termos da distribuição da quantidade de buscas com determinados termos ao longo do tempo. A quantidade de buscas é quantificada, por meio de um índice de buscas que varia entre 0 e 100. Para analisar como o isolamento social repercutiu nas mudanças culinárias, relacionamos os resultados do isolamento com duas buscas por termos que pudessem ser elucidativos de mudanças na alimentação: 1) buscas por "receitas" (culinárias); 2) comparação entre as buscas pelos termos "pão" x "bolo".

A comparação da busca pelos termos "pão" x "bolo" se justifica pelo fato de ter sido identificado um aumento da preparação desses alimentos durante a pandemia acarretando, inclusive, a falta de farinha e fermento nas prateleiras dos mercados. Segundo matéria do Estado de São Paulo (MENGUE, 2020), esse fenômeno se repetiu em outros países, como Estados Unidos.

\section{$O$ ato de cozinhar em casa durante o período de isolamento social}

O primeiro caso confirmado de COVID-19, no Brasil, surgiu em São Paulo, em 24 de fevereiro, recém-chegado da Itália. As primeiras iniciativas de isolamento ocorreram em alguns estados, em 16 de março, quando constatou-se a primeira morte acarretada pelo vírus. O fechamento de serviços não essenciais ocorreu em 24 de março. O Gráfico 1 apresenta o movimento do índice brasileiro de isolamento social diário ao longo do tempo, desde 2 de fevereiro de 2020 no Brasil. Com o objetivo de suavizar variações semanais, apresentamos apenas os números referentes aos domingos. Chama a atenção o fato de que o maior índice de isolamento $(62,2 \%)$ ocorreu em 22 de março, isto é, pouco menos de uma semana após o início da quarentena. Após essa data, o índice oscilou um pouco abaixo de 50\%, atingindo 47,9\% em 20 de agosto.

\footnotetext{
${ }^{7}$ Website institucional: https://www.inloco.com.br/ (Mapa de Isolamento Social | COVID-19 | Coronavírus no $\underline{\text { Brasil | Inloco) }}$
} 
Gráfico 1: Índice de Isolamento Social no Brasil entre os meses fevereiro e agosto

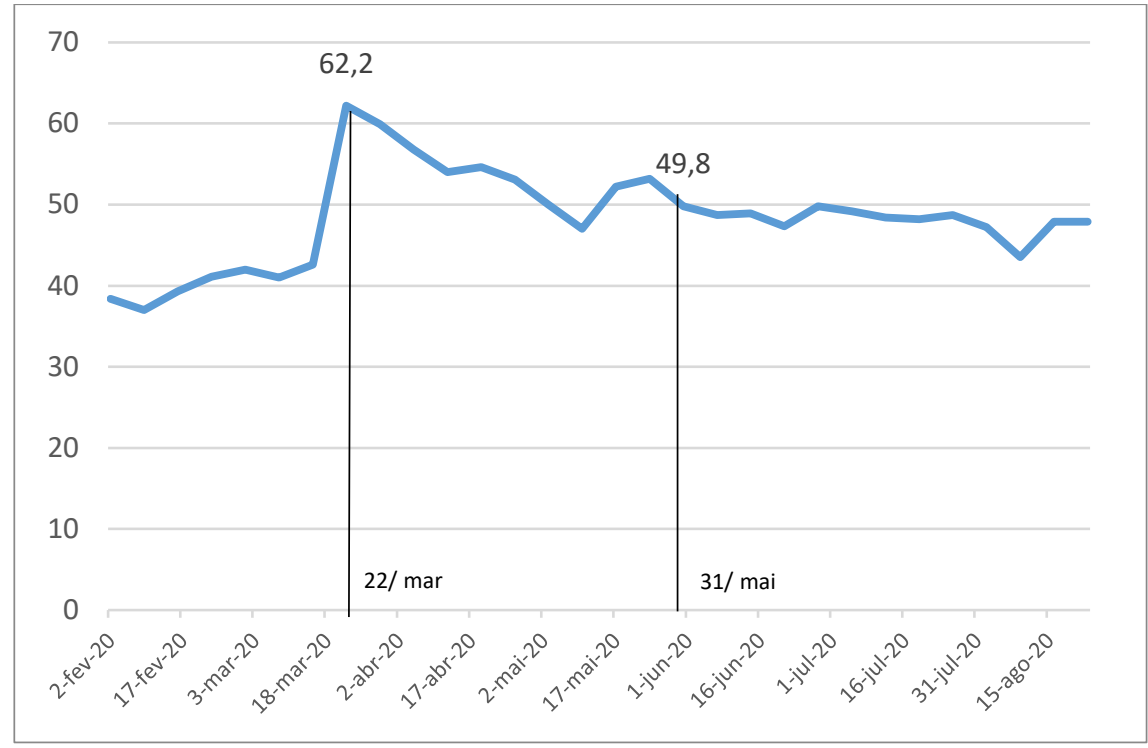

Fonte: InLoco

O Gráfico 2 apresenta a busca pelo termo "Receita" no Google Trends para o mesmo período do gráfico 1, de fevereiro a agosto. Como pode ser visto, assim como no índice de isolamento social, o dia 22 de março coincidiu com a maior quantidade de buscas (índice de 100) no Google. A partir dessa data, as buscas variaram, contudo se mantiveram acima do maior índice de buscas, no período antes do isolamento social. Este resultado sugere uma correlação direta entre isolamento social e busca por receitas.

Gráfico 1: Buscas pelo termo "Receita" (culinária) no Google

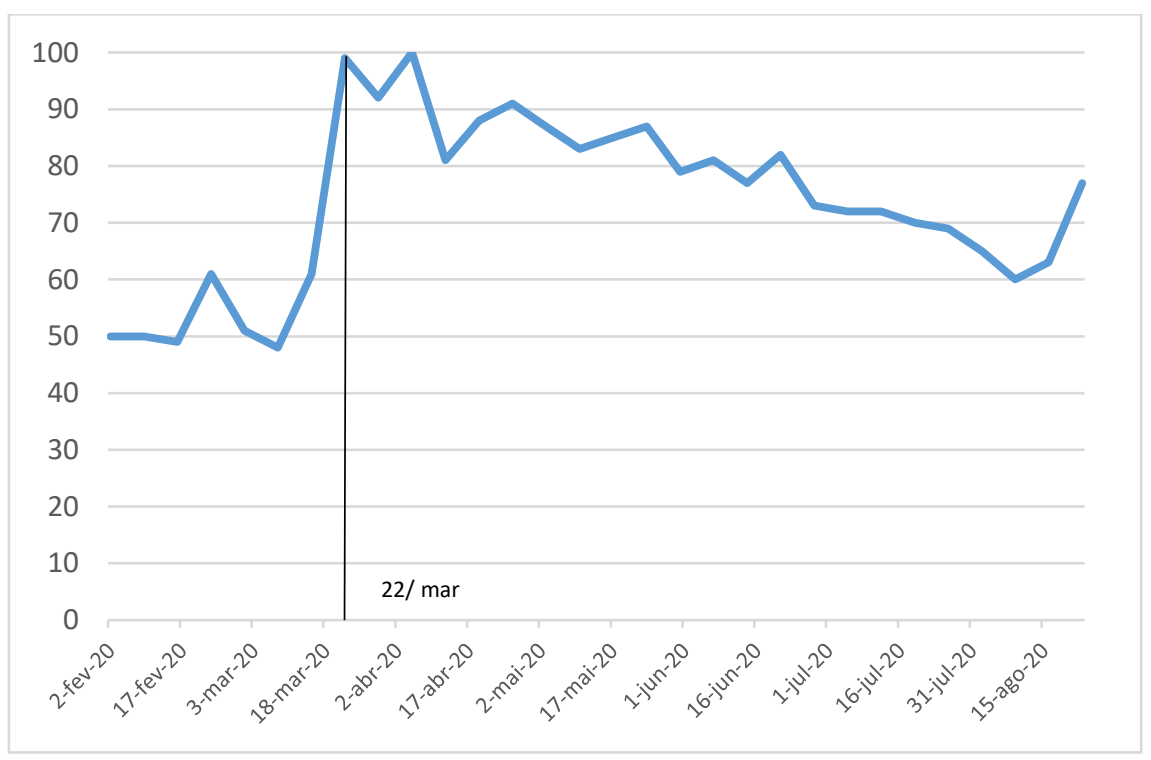

Fonte: Google Trends 
Para verificar a correlação entre o isolamento e as buscas por receitas, o Gráfico 3 apresenta a variação, ao longo do tempo, entre essas duas variáveis, de modo que no eixo x estão os dados do índice de isolamento social - variando de 37,0\% a 62,2\%; e no eixo y estão os dados de busca pelo termo "receitas" culinárias no Google, que variam entre 48 e 100 (o Google Trends atribui 100 ao nível máximo de buscas por um termo). Os pontos azuis ao redor da reta se referem às semanas entre 2 de fevereiro e 23 de agosto.

Gráfico 2: Correlação entre buscas pelo termo "Receita" (culinária) no Google e índice de isolamento social

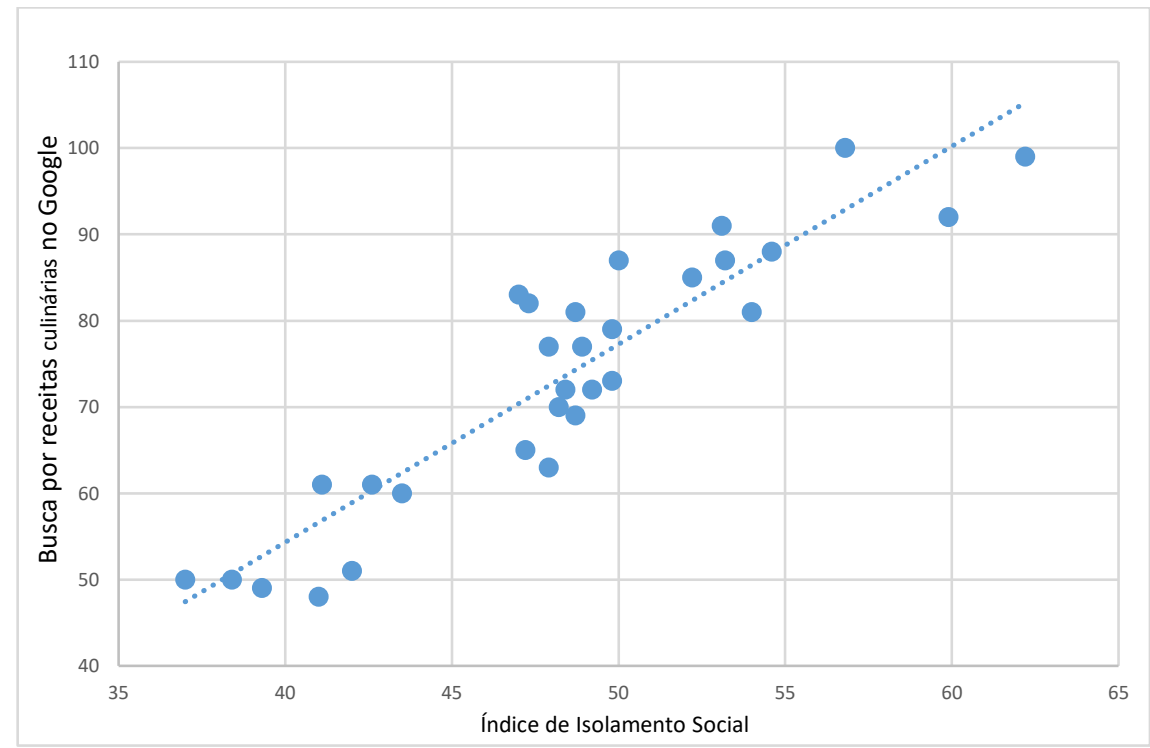

Fonte: Google Trends e InLoco

Neste gráfico, fica clara a alta correlação entre essas duas variáveis, atingindo um valor de 0,84. Com isso, pode-se afirmar que a busca por receitas culinárias foi uma das características do isolamento social, demonstrando um papel importante da Internet e das redes sociais digitais como potenciais ferramentas para desenvolver e aprimorar as habilidades culinárias no contexto da pandemia.

\section{O potencial da Gastronomia na promoção das habilidades culinárias}

Além de identificar essa mudança no preparo das refeições durante o isolamento social, buscamos analisar o potencial da Gastronomia em ampliar os conhecimentos e habilidades culinárias da população. 
Diversas notícias de jornal apresentam e discutem como a culinária ganhou grande destaque na vida das famílias durante a pandemia. Seja por hobby, diversão ou necessidade, preparar seu alimento ganhou um espaço muito maior na vida das famílias. Como mais um resultado que reforça essa constatação, está o fenômeno da preparação de pães e bolos em casa o que acarretou, inclusive, uma falta de fermento nos mercados. Segundo Cunha (2020), o produto teve seu estoque diminuído em $29,8 \%$ e o preço subiu $72,2 \%$, em relação a fevereiro. Conforme demonstra a Gráfico 4, houve um aumento significativo na busca por receitas de bolo e pão no período da pandemia. Mais uma vez, o dia 22 aparece como um marco importante de pico no índice de buscas dessas receitas (bolo com 96 e pão com 32). Em agosto, passados mais de cinco meses do início do isolamento, os índices continuaram mais altos que antes desse momento.

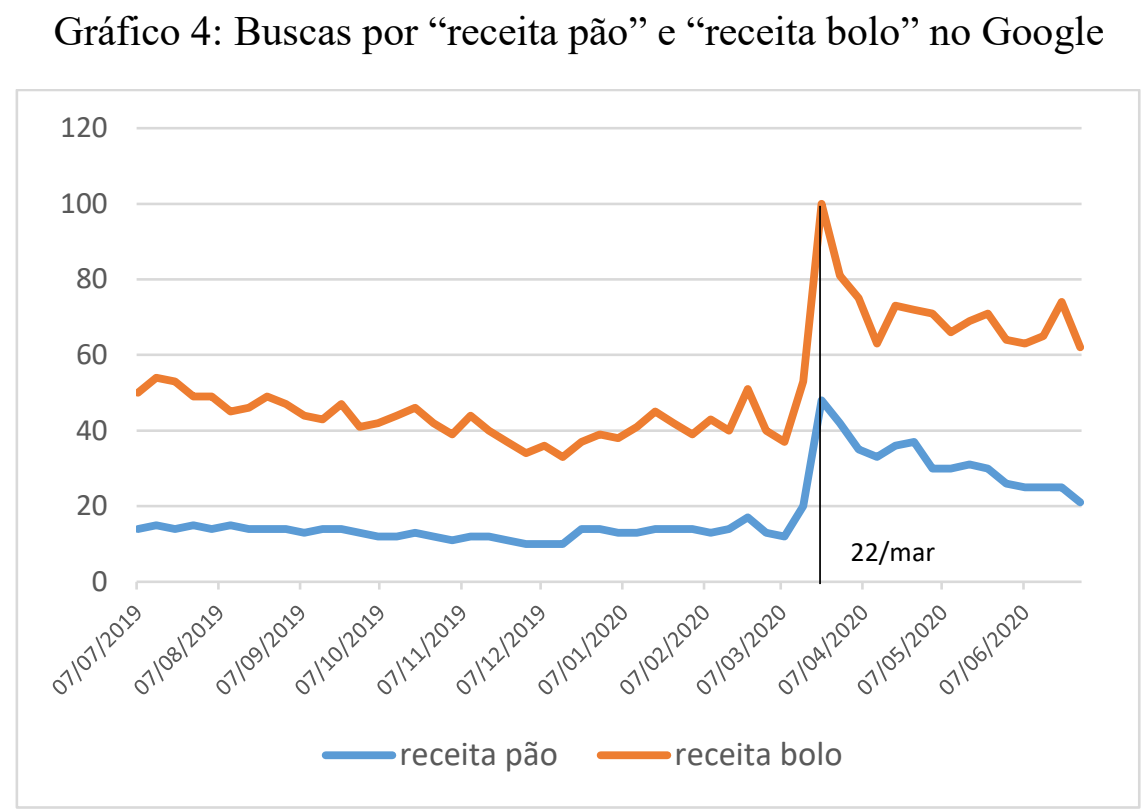

Fonte: Google Trends

\section{Algumas considerações}

Com base nos resultados, é possível verificar uma forte correlação entre as buscas por receitas culinárias na Internet e o período de isolamento social, tendo como um marco o dia 22 de março, em que tanto as buscas por receitas como o isolamento assumiram seu pico. É importante ressaltar que mesmo com a queda do isolamento - e consequente queda nas buscas por receitas o índice de buscas por receitas continuou maior do que pico anterior à pandemia (referente aos períodos de festas de fim de ano). É possível afirmar que, desde março, os brasileiros vêm se 
"aventurando" na cozinha e, portanto, desenvolvendo habilidades culinárias que, nas palavras de Giard (1996), envolvem o saber prático relacionado aos procedimentos físicos que complementam o saber intelectual na hora de cozinhar. Essas habilidades envolvem um aprendizado que vai para além de conhecimentos sobre o preparo de uma receita, como algo a ser desempenhado de forma técnica e mecânica. Os conhecimentos construídos ao longo desse processo incluem a escolha dos alimentos que irão compor essa receita, o tempo de cocção, as diferentes técnicas de preparo, a mistura de sabores. Com isso, conforme valorizado no Marco Referencial da EAN, essa experiência culinária, de médio prazo, vem se constituindo como uma "prática emancipatória" (BRASIL 2012), na medida em que tem garantido autonomia, cuidado e autocuidado.

O conhecimento culinário que, tendo uma forte questão de gênero associada, anteriormente era passado por mães e avós para mulheres. A atualmente, em função do estilo de vida contemporânea, vem sendo ocupado pela Internet e a consequente ampliação das trocas culinárias no ambiente digital, especialmente em mídias sociais como Instagram e Youtube. Nesse espaço, é possível buscar e comparar as receitas de pratos preferidos, conhecer receitas e comidas de qualquer lugar do mundo e aprender sobre hábitos e culturas diferentes. Essa possibilidade de ampliar as habilidades culinárias é repercutida e compartilhada em tempo real no ambiente digital, o que tende a inspirar outras pessoas a ingressar na cozinha.

Outra característica relacionada às habilidades culinárias, nesse momento pandêmico, se manifestou na tendência de buscas por receitas de bolos e pães. Essas buscas tiveram seu pico também na semana de 22 de março (100 e 48, respectivamente) e houve um aumento significativo durante todo o período de isolamento em relação ao período anterior. $\mathrm{O}$ crescimento na produção de alimentos de panificação foi verificado em outros países, acarretando, no Brasil, uma elevação de $83,2 \%$ na procura por fermento biológico (para produção de pães) e 30,9\% na procura de fermento químico (para bolos e biscoitos) (BOUÇAS; SOUZA, 2020). Esses alimentos em que a massa sofre um processo de fermentação trazem uma sensação de conforto e de afeto.

Embora não seja escopo deste artigo, é importante investigar como as relações de gênero se estabelecem, neste momento de pandemia, em relação ao ato de cozinhar. Diversos artigos apontam a sobrecarga de trabalho feminino associado aos cuidados domésticos durante o isolamento social (FRANÇA, PRIORI, GALINKIN, 2020; GUEDES, CARVALHO, 2020; BORJES, 2020; BRASIL, 2020). Contudo, para analisar como este momento vem acarretando mudanças na relação de gênero com a cozinha, é necessário que outras pesquisas sejam realizadas.

Dessa forma, ainda não é possível saber como essas mudanças em relação às habilidades culinárias durante esse período acarretarão mudanças no pós-pandemia. Consideramos que para 
que se mantenham, posteriormente, são necessárias mudanças complexas na organização do trabalho e do tempo fora de casa. Portanto, avaliamos que a aquisição de habilidades culinárias não é suficiente para garantir essa permanência. Contudo, , acreditamos que esse movimento de "entrada na cozinha", acarretado pela pandemia, tem como potencial desenvolver mudanças em três principais aspectos: alimentação mais saudável, uma vez que as habilidades culinárias possibilitam um menor consumo de alimentos ultraprocessados; aproximação com o alimento e com a culinária, permitindo desenvolver a aprendizagem e/ou o prazer com essa atividade, possibilitando a criação de novos sentido e sabores; o ensino dessas habilidades para as futuras gerações.

O conceito ampliado de gastronomia e os diálogos possíveis com o campo da SSAN oferece uma lente para olhar para esse momento como uma alternativa para fortalecer as estratégias de promoção da EAN com uma perspectiva dialógica e problematizadora, reconhecendo a necessidade da ação política dos processos educativos e de comunicação para que a comida de verdade seja uma realidade concreta para toda a população.

Por fim, mesmo compreendendo a retórica apresentada na presente pesquisa, na qual se observou o potencial relacionamento do ato de cozinhar com o período de isolamento social, alguns estudos destacam uma outra realidade já prevista para esse cenário, apontando uma piora nos hábitos alimentares da população brasileira durante esse período, com a diminuição de consumo de hortaliças, frutas e verduras e aumento no consumo de processados (MATAL et al, 2020; FIOCRUZ, 2020). Dito isso, percebe-se que a sociedade enfrentou o momento da pandemia de forma desigual, pois a crise gerada pelo contexto adverso impôs realidades diversas, nas quais muitas pessoas sofreram com a falta de renda, e com a falta de assistência governamental, e que as escolhas alimentares foram baseadas nas relações de custo e benefício, colocando a nossa discussão em um cenário privilegiado, ao se referir a uma parcela da sociedade que pode exercer o isolamento e dispor de recursos para manter sua rotina alimentar. Portanto, a proposta em aproximar a Gastronomia com a SSAN tem o intuito de refletir sobre as potencialidades de ações transdisciplinares que promovam o Direito Humano à Alimentação Adequada para toda a população. 


\section{Referências}

ASLAM, Salman. Instagram by the Numbers: Stats, Demographics \& Fun Facts. Omnicore Agency.10 de Fev de 2020. Disponível em: <https:/www.omnicoreagency.com/instagramstatistics>. Acesso em: 30 ago. 2020.

BORGES, Maria José Rigotti. O vírus e o invisível: a desigualdade de gênero e o trabalho de cuidado. Rev. Trib. Reg. Trab. $3^{\text {a }}$ Reg., Belo Horizonte, edição especial, p. 265-310, 2020.

BOUÇAS, Cibele; SOUZA, Marcos de Moura. Brasileiro busca comida reconfortante: Confinamento estimulou brasileiros a cozinhar em casa e aqueceu a indústria. Valor Econômico, São Paulo, p. 1-1, 6 jul. 2020. Disponível em: https://valor.globo.com/empresas/noticia/2020/07/06/brasileiro-busca-comidareconfortante.ghtml. Acesso em: 30 ago. 2020.

BRASIL. Ministério da Saúde (MS). Ministério da Previdência e Assistência Social. Relatório Final da $8^{\text {a }}$ Conferência Nacional da Saúde Brasília: MS; 1986.

. Ministério da saúde. As cartas da promoção da saúde. Brasília: Ministério da Saúde, 2002. Disponível em: < https://bvsms.saude.gov.br/bvs/publicacoes/cartas_promocao.pdf $>$. Acesso em 05 jan. 2021.

Presidência da República. Casa Civil. Subchefia para Assuntos Jurídicos. Lei no 11.346, de 15 de setembro de 2006. Cria o Sistema Nacional de Segurança Alimentar e Nutricional SISAN com vistas em assegurar o direito humano à alimentação adequada e dá outras providências. Disponível em: http://www.planalto.gov.br/ccivil_03/_ato20042006/2006/lei/111346.htm. Acesso em 05 jan 2021.

Conselho Nacional de Segurança Alimentar. Manifesto Comida de Verdade. V Conferência Nacional de Segurança Alimentar e Nutricional (CONSAN). Brasília (DF), 2015.: <http://goo.gl/QRxOht>. Acesso em: 11 jul. 2019.

Conselho Nacional de Segurança Alimentar. Presidência da República CONSEA Nacional. GT Alimentação Saudável, Relatório Final, março de 2007. Brasília - DF. Disponível em: <https://bit.ly/2SgcvbC>. Acesso em: 11 jul. 2019.

Ministério da Saúde. Secretaria de Atenção à Saúde. Departamento de Atenção Básica. Guia alimentar para a população brasileira. 2. ed. Brasília - DF, 2014. < http://bvsms.saude.gov.br/>. Acesso em: 11 jul. 2019

Instituto Brasileiro de Geografia e Estatística (IBGE). Pnad sobre trabalhos domésticos, jun 2020. Disponível em: < https://agenciadenoticias.ibge.gov.br/agencia-sala-deimprensa/2013-agencia-de-noticias/releases/27877-em-media-mulheres-dedicam-10-4-horaspor-semana-a-mais-que-os-homens-aos-afazeres-domesticos-ou-ao-cuidado-de-pessoas $>$. Acesso em 30 ago 2020.

Ministério do Desenvolvimento Social e Combate à Fome. Marco de referência de educação alimentar e nutricional para as políticas públicas. Brasília: MDS; 2012 Disponível em:

http://www.mds.gov.br/webarquivos/arquivo/seguranca_alimentar/caisan/Publicacao/Educacao_ Alimentar_Nutricional/1_marcoEAN.pdf. Acesso em: 30 ago. 2020. 
BUSS, M. Marchiori. Uma introdução ao conceito de promoção da saúde. In: Czeresneia, D.; FREITAS, M.C. (Orgs). Promoção da saúde: conceitos, reflexões, tendências. p. 19-42. Rio de Janeiro: Ed. FioCruz, 2009.

BRILLAT-SAVARIN, Jean Anthelme. A Fisiologia do Gosto. Trad.: Paulo Neves. $5^{\text {a }}$ reimp. São Paulo: Cia das Letras, 1995.

CARDOSO, William. Marmita vira o ganha pão de quem luta para superar a crise do coronavírus. Folha de São Paulo. 27de abr 2020. Disponível em: <https://agora.folha.uol.com.br/saopaulo/2020/04/marmita-vira-o-ganha-pao-de-quem-luta-para-superar-a-crise-do-

coronavirus.shtml>. Acesso em: 30/08/2020

CASTRO, Helisa Canfield, MACIEL, Maria Eunice, MACIEL, Rodrigo Araújo. Comida, cultura e identidade: conexões a partir do campo da gastronomia. Ágora, v. 18, n. 1, p. 18-27, 2016.

CERTEAU, Michel; GIARD, Luce; MAYOL, Pierre. A Invenção do cotidiano. 2. Morar, cozinhar. Trad.: Ephraim F. Alves e Lúcia Endlich Orth. 10ª ed. Petrópolis (RJ): Vozes, 2011.

CUNHA, Lilian. Pandemia muda comportamento de compra e eleva falta de produtos no varejo. 6 minutos - UOL, São Paulo. 28/05/2020. Disponível em: $<$ https://6minutos.uol.com.br/economia/pandemia-muda-comportamento-de-compra-e-elevafalta-de-produtos-no-varejo/>. Acesso em: 30/08/2020

FIOCRUZ. FUNDAÇÃO OSW ALDO CRUZ. Nota técnica n 5 de 20 de maio de 2020. Regiões e Redes Covid-19: Acesso aos serviços de saúde e fluxo de deslocamento de pacientes em busca de internação. Disponível em: https://bigdata-covid19a.icict.fiocruz.br/nota_tecnica_7.pdf. Acesso em: 20 Jan. 2021.

FOLHA VITÓRIA (Espirito Santo). Diário da Quarentena: cozinhar é uma forma de distração durante a pandemia. Folha Vitória, Vitória - ES, p. 1-1, 5 jun. 2020. Disponível em: https://www.folhavitoria.com.br/geral/noticia/06/2020/diario-da-quarentena-cozinhar-e-umaforma-de-distracao-durante-a-pandemia. Acesso em: 30 ago. 2020.

FRANÇA, Fabiane Freire, PRIORI, Claudia, GALINKIN, Ana Lúcia. Os impactos da pandemia (Covid-19) no cotidiano das pessoas: desafios e contribuições dos estudos de gênero e dos feminismos-Entrevista com Joana Maria Pedro. Revista Educação e Linguagens, p. 11-25, 2020.

FRANCO, Areovaldo. De caçador a gourmet: uma história da gastronomia. Thesaurus Editora, 2001.

FREIXA, Dolores, CHAVES, Guta. Gastronomia no brasil e no mundo.2. Ed. 3. Reimpr. Rio de janeiro: senac nacional, 2013.

GIARD, Luce. Cozinhar. In: CERTEAU, Michel.; GIARD, Luce.; MAYOL, Pierre. A invenção do cotidiano: 2 - Morar, cozinhar. Petrópolis: Vozes, 1996, pp. 211-332.

GILlESPIE, Cailein, COUSINS, John A. European Gastronomy into the 21st Century. Butterworth-Heinemann, Oxford. 2001.

GUEDES, Moema de Castro, CARVALHO, Mariana de Carvalho. Confinamento, desigualdade e trabalho: o cuidado como atributo feminino. Publicação no site do Programa de Pós-Graduação de Ciências Sociais, em 6 de julho de 2020. Disponível em: http://ppgcs.ufrrj.br/wpcontent/uploads/2020/07/Confinamento-desigualdade-e-trabalho-o-cuidado-como-atributofeminino_Moema-e-Marina.pdf. 
HORTA, Nina. Não é sopa. $2^{a}$ ed. Rio de Janeiro: Companhia da Mesa, 2020 (e-book).

KOWALTOWSKI, Alicia. Como comer durante a pandemia. Nexo Jornal. 06 de mai de 2020. Disponível em: <https://www.nexojornal.com.br/colunistas/2020/Como-comer-durante-apandemia>. Acesso em: 30/08/2020.

MALTA, Deborah Carvalho et al. A pandemia da COVID-19 e as mudanças no estilo de vida dos brasileiros adultos: um estudo transversal, 2020. Epidemiol. Serv. Saúde, Brasília, v. 29, n.4, 2020. Disponível em: <http://www.scielo.br/scielo.php?script=sci_arttext\&pid=S223796222020000400315\&lng=en\&nrm=iso>. Acesso em: 23 Jan. 2021.

MALUF, R. Rede Brasileira de Pesquisa em SSAN. 6 nov. 2017. Disponível em: https://fbssan.org.br/2017/11/rede-brasileira-de-pesquisa-em-ssan/. Acesso em: 05 jan 2021.

MATTA, Raúl. República gastronómica y país de cocineros: comida, política, medios y una nueva idea de nación para el Perú. Revista colombiana de antropología, v. 50, n. 2, p. 15-40, 2014.

MENGUE, Priscila. Na quarentena, assar pão e bolo ganha espaço e aumenta procura por farinha. O Estado de São Paulo. 06 de abril de 2020. Disponível em: $<$ https://saude.estadao.com.br/noticias/geral,na-quarentena-assar-pao-e-bolo-ganha-espaco-eaumenta-procura-por-farinha,70003261439>. Acesso em: 30 ago. 2020.

NOGUEIRA, Marcos. Saber cozinhar pode salvar sua vida na pandemia. Folha de São Paulo 14.mar.2020. Disponível em: <https://cozinhabruta.blogfolha.uol.com.br/2020/03/14/sabercozinhar-pode-salvar-sua-vida-na-pandemia/?loggedpaywall>. Acesso em 30/08/2020.

PELERANO, Joana. Aprendendo a cozinhar: como o conhecimento culinário é compartilhado nos dias de hoje. VII Encontro Nacional de Estudos do Consumo III Encontro Luso-Brasileiro de Estudos do Consumo I Encontro Latino-Americano de Estudos do Consumo. Anais. Puc-Rio, set. 2014. Disponível em: <https://estudosdoconsumo.com/wp-content/uploads/2018/05/ENEC2014GT05-Pellerano-Aprendendo_a_cozinhar.pdf>. Acesso em 30 ago. 2020..

PETRINI, Carlo. Loving the Earth: Dialogues on the future of our planet. Itália: Slow Food Editore, 2014.

Slow Food: princípios da nova gastronomia. Trad.: Renata Lucia Botini. São Paulo: Ed. São Paulo, 2009.

POULAIN Jean-Pierre. Sociologias da alimentação: os comedores e o espaço social alimentar. $2^{\mathrm{a}}$ ed. Florianópolis: Editora da UFSC; 2013. 285 p

RIO DE JANEIRO. Projeto de Lei No 1042/2015 de 10 de Outubro 2015. Marco Referencial da Gastronomia como Cultura e dá Outras Providências. Rio de Janeiro, RJ, dez 2015. Disponível em:

http://alerjln1.alerj.rj.gov.br/scpro1519.nsf/18c1dd68f96be3e7832566ec0018d833/f332cf60e79e 46aa83257ee60050. Acesso em: 30 ago. 2020.

RIZZOLO, Anelize.; OLIN, Priscila.; REIS, Ana Beartriz.; PEREIRA, Maína. Comensalidade em Tempos de Pandemia de COVID-19 Relatório Parcial. Universidade de Brasília (UNB): Observatório de Políticas de Segurança Alimentar e Nutricional MultiplicaSSAN, 2020. Disponível em: < https://multiplicassan.wixsite.com/multiplica/post/comensalidade-em-temposde-pandemia $>$. Acesso em 05 jan.2021. 
SANTAELLA, Lucia. A ecologia pluralista da comunicação: conectividade, mobilidade, ubiquidade. SP: Paulus, 2010.

SANTICH, Barbara. Sustaining Gastronomy. In: Proceedings of the Eighth Symposium on Australian Gastronomy: Sustaining Gastronomy, Adelaide, 28-30 September, 1994, pp. 1-2. 1996

. The study of gastronomy and its relevance to hospitality education and training. International journal of hospitality management, v. 23, n. 1, p. 15-24, 2004.

SOARES, Cláudia Mesquita Pinto. Conceitos de Gastronomia: um debate sobre dissonâncias e convergências na literatura científica. Rev. Confluências Culturais, Santa Catarina, v. 9, ed. 2, 2020.

TUCHLINSKI, Camila. Comida e afeto: como a gastronomia está aproximando pais e filhos. Estado de São Paulo. 12 de julho de 2020. Disponível em: <https://cultura.estadao.com.br/noticias/geral,comida-e-afeto-como-a-gastronomia-estaaproximando-pais-e-filhos,70003359906>. Acesso em: 30/08/2020. 